\title{
Advanced biorefinery in lower termite-effect of combined pretreatment during the chewing process
}

Jing Ke, Dhrubojyoti D Laskar, Difeng Gao and Shulin Chen*

\begin{abstract}
Background: Currently the major barrier in biomass utilization is the lack of an effective pretreatment of plant cell wall so that the carbohydrates can subsequently be hydrolyzed into sugars for fermentation into fuel or chemical molecules. Termites are highly effective in degrading lignocellulosics and thus can be used as model biological systems for studying plant cell wall degradation.

Results: We discovered a combination of specific structural and compositional modification of the lignin framework and partial degradation of carbohydrates that occurs in softwood with physical chewing by the termite, Coptotermes formosanus, which are critical for efficient cell wall digestion. Comparative studies on the termitechewed and native (control) softwood tissues at the same size were conducted with the aid of advanced analytical techniques such as pyrolysis gas chromatography mass spectrometry, attenuated total reflectance Fourier transform infrared spectroscopy and thermogravimetry. The results strongly suggest a significant increase in the softwood cellulose enzymatic digestibility after termite chewing, accompanied with utilization of holocellulosic counterparts and an increase in the hydrolysable capacity of lignin collectively. In other words, the termite mechanical chewing process combines with specific biological pretreatment on the lignin counterpart in the plant cell wall, resulting in increased enzymatic cellulose digestibility in vitro. The specific lignin unlocking mechanism at this chewing stage comprises mainly of the cleavage of specific bonds from the lignin network and the modification and redistribution of functional groups in the resulting chewed plant tissue, which better expose the carbohydrate within the plant cell wall. Moreover, cleavage of the bond between the holocellulosic network and lignin molecule during the chewing process results in much better exposure of the biomass carbohydrate.

Conclusion: Collectively, these data indicate the participation of lignin-related enzyme(s) or polypeptide(s) and/or esterase(s), along with involvement of cellulases and hemicellulases in the chewing process of C. formosanus, resulting in an efficient pretreatment of biomass through a combination of mechanical and enzymatic processes. This pretreatment could be mimicked for industrial biomass conversion.
\end{abstract}

\section{Background}

Transformational scientific knowledge on bioprocessing is required for developing enabling technologies toward converting renewable biomass to targeted biofuels or biochemicals. A major barrier in biomass utilization is the lack of an effective pretreatment of plant cell wall (PCW) so that the carbohydrates can subsequently be hydrolyzed into sugars to be fermented into fuel or chemicals. Existing technologies typically employ thermochemical

\footnotetext{
* Correspondence: chens@wsu.edu

Department of Biological Systems Engineering, Washington State University, Pullman, Washington 99164-6120, USA
}

processes for biomass pretreatment to break down the barriers formed by lignin and lignin-hemicellulose association. Although effective, these processes are energy intensive, environmentally unfavorable and associated with the production of inhibitors that compromise the performance of downstream fermentation. The fact that there is still no successfully demonstrated commercial system in the world for producing biofuels and biochemicals from lignocellulosic biomass underscores the magnitude of the related technical challenges. There is an urgent need for new systems that are more efficient, 
cost-effective and environmentally-friendly for deconstructing PCW for sugar release.

Nature, through millions of years' evolution, has developed highly efficient biological systems. Wood-feeding termites (Insecta, Isoptera) are among the most effective lignocellulose-recycling invertebrates in terms of the rate and extent of cellulose utilization [1]. Termites work as a complete PCW deconstruction system and are considered to be highly effective for wood degradation as they requires only biomass, moisture and air to function efficiently. Termites' unique mechanisms could serve as an ideal bioconversion model and a novel source of catalysts for refining biofuels and biochemicals. Recently, their ability to convert recalcitrant PCW into a useable energy source of monomer sugars has attracted much interest in the biofuel area [2]. Lower termites are believed to utilize lignocellulosic carbohydrates in a step-wise fashion using cellulases and hemicellulases, with help from lignolytic enzymes [3-6]. However, the pretreatment mechanism of the lignin matrix during the whole digestive process is as of yet unexplored. In addition, the selective modifications to the lignin-hemicellulose matrix for subsequent cellulose hydrolysis have not yet been explored. Lack of such knowledge is a major barrier to the efficient pretreatment of biomass required to enable substantial biomass utilization.

In exploring the mechanisms of PCW degradation by termites, it has always been speculated that the termite chewing action plays an important role in the initial pretreatment. Fujita et al. [7] have already demonstrated one of the characteristics of wood degradation by termites to be the mechanical grinding of food by the mandibles to increase the surface area of the substrates. The termite workers chew wood blocks into small particles at an early stage of the digestion process for better access to carbohydrates. During this mechanical grinding of the wood particles, cellulases append to the wood particles or mix with them to initiate the catalysis process [8]. Yoshimura demonstrated that the lower termite Coptotermes formosanus crushes and grinds the wood to exhibit sharp edges on the surface, allowing better accessibility by the functional enzymes [3]. It has been reported that termite workers in the Rhinotermitidae family excavate the wood for nesting [9]. When they were moved to a new environment with only wood blocks, they continued their chewing behavior to acquire a large amount of small wood particles for nesting. The nest consisted of ground wood particles pasted together with a special secretion from the salivary glands $[9,10]$. A large proportion of these particles might be re-digested. During the chewing process, the workers released secretions from their salivary and labial glands for the initial digestion and community activity of feeding stimulation [11].
Termite saliva, which is used for claying of nesting materials, has been reported in previous studies to contain various digestive enzymes. Fujita et al. have already cloned two cDNAs that encode premature lysozyme peptides (Rs-Lys1 and Rs-Lys2) from workers of a Japanese damp-wood termite, Reticulitermes speratus [12]. Moreover, they demonstrated that the total digestive lysozyme activity is termite in origin and predominates in the salivary glands and, to a minor extent, in the digestive tract. At the same time, Nakashima et al. found $80.8 \%$ of total cellulase activity stemmed from the salivary glands of $C$. formosanus [13]. Cellobiase is also reported to occur in the salivary glands of Mastotermes darwiniensis and Neotermes koshunensis $[14,15]$. It has been proposed that cellulose is first degraded to some extent by carboxymethyl cellulase produced in the salivary glands of termites, and then ingested by protozoa, which finally decompose the cellulose to glucose with their own endo-beta-1,4-glucanases, exo-cellobiohydrolase, and $\beta$-D-glucosidase $[3,16]$. For the digestion of hemicelluloses, Inoue et al. demonstrated endo- $\beta-1,4-$ xylanase activity in the salivary glands of the lower termite $R$. speratus, however, no $\beta$-xylosidase activity was documented [17]. For lignin degradation, laccase and phenoloxidase gene expression, as well as benzene-1,2,3triol oxidation activity, were confirmed in the salivary gland of $R$. flavipes [18].

In termites, the labial glandular ducts open into the oral cavity, from which the watery labial gland secretion is released onto the wood [11]. The labial gland secretion, which contributes to the saliva, is reported to have various species-specific functions in nest construction, as a social nutrient and as a source of digestive enzymes [11,14,19-21]. During communal food exploitation, the labial gland secretion is released onto the food by feeding workers, as demonstrated in the African termite Schedorhinotermes lamanianus and the French species $R$. santonensis [22-24], thereby aiding in efficient food exploitation.

It is important to note that current research on lignin modification by termites is mainly focused on the gut process of digestion. Such studies are centered towards the understanding of the symbiont evolution, transcriptomics, meta-transcriptomics and metagenomics of wood-feeding termites, which are necessary for understanding the lignocellulose degradation process. However, there have been no reports nor has attention been drawn towards understanding the combined process of biological lignin modification and physical chewing for cellulose release during the chewing process in termites, which is essential to target the fundamental hurdle in producing cellulosic biofuels-overcoming the barriers of enzymatic hydrolysis of cellulose. In an earlier report, we have already evaluated the possible deconstruction 
pattern of hardwood lignocellulosics in the clearwing borer system [25]. Here, we expand our investigation of biological lignocellulosic modification during the chewing stage of wood-feeding termites. The purpose of this study is to determine the associated structural changes of the softwood during the mechanical chewing process of the $C$. formosanus termite, and provide new insight into designing new pretreatment processes for biomass conversion. The analysis methods include compositional analysis, enzymatic hydrolysis, pyrolysis gas chromatography mass spectrometry (Py-GC/MS), attenuated total reflectance Fourier transform infrared (ATR-FTIR) spectroscopy and thermogravimetry (TG/DTG) analysis.

\section{Results and discussion}

Monomer sugar release in termite-chewed softwood The free monomeric sugars existing in the termitechewed wood particles, as well as that in the ball milled softwood control, are presented in Table 1. Compared to the artificially ball milled softwood, both the free six carbon (C6) and C5 sugar increased by more than ten times in the chewed softwood, which indicates initial hydrolysis of cellulose and hemicelluloses by termite-originated enzymes. The speculation is that, during the chewing process, termites release digestive enzymes, here including cellulolytic and hemicellulolytic enzymes, onto the chewed particles. A proportion of the sugar is to be further metabolized and the remaining part is liberated from the termite oral cavity with the chewed wood particles for nest construction, together with salivary and/or labial gland secretions. The cellulolytic and hemicellulolytic enzymes attached to the wood particles will continue catalyzing hydrolysis of the cellulose and hemicelluloses, which will cause the free monomer sugars to accumulate in the termite-chewed particles.

\section{Compositional changes in chewed softwood}

For the control and termite-chewed softwood tissues in this study, lignin concentrations were estimated using acetyl bromide $(\mathrm{AcBr})$ extinction coefficients as previously demonstrated [6]. The AcBr analysis determined the lignin content to be $20.83 \%$ and $22.81 \%$ for control and termite-chewed softwood cell wall residues (CWRs), respectively (Table 2 ). Interestingly, a slight increase in the lignin content was observed in the softwood tissues after the process of chewing by termites. This increase in the lignin content is possibly due to the relative decrease in the amount of the holocellulosic counterparts in the PCW after grinding by termites, that is, cellulose and/or hemicellulose were preferably degraded and/or utilized by the termites during the chewing process. These findings demonstrate the restricted capacity of lignin degradation during the chewing process of softwood tissues in termites.

To support such a possibility, chemical compositional analyses on the softwood tissues were carried out to evaluate the relative amounts of acid-soluble and insoluble lignin, together with C6 and C5 carbohydrates, prior to and after the chewing process in termites (Table 2). Thus, the calculated acid-soluble lignin content (expressed as percentage weight of initial biomass) after dilute $\mathrm{H}_{2} \mathrm{SO}_{4}$ acid hydrolysis were $2.62 \%$ and $3.78 \%$ for the control and termite-chewed softwood tissues, respectively. The $10 \%$ increase in lignin content, as observed in the AcBr analysis, correlates with the 44\% increase in acid-soluble lignin content, which is speculated to reveal an increase in the hydrolysable capacity of lignin in softwood after the termite chewing process. Meanwhile, the respective decreases of the C6 and C5 sugars in the chewed sample, by $32.8 \%$ and $34.7 \%$ respectively, supports the previous conclusion that cellulolytic and hemicellulolytic enzymes are released during the termite chewing process, catalyzing the hydrolysis of cellulose and hemicelluloses; the majority of the released sugars are assimilated by the termites.

\section{Potential change of enzymatic sugar release after termite chewing}

As Figure 1A shows, the chewed sample showed more rapid release of C6 sugars over the first 12 hours of hydrolysis than the control sample. Thus, the termite chewing process can be considered to have a pretreatment effect on the lignin-hemicellulose matrix, exposing the cellulose to enzyme activity to a greater degree than

Table 1 Monomer sugars washed from termite-chewed softwood and undigested control.

\begin{tabular}{|c|c|c|}
\hline Sugar & Undigested softwood $\left(\times 10^{-8}, \mathrm{~g} / \mathrm{g}\right)$ & Termite-chewed softwood $\left(\times 10^{-8}, \mathrm{~g} / \mathrm{g}\right)$ \\
\hline Fucose & NA & $5.35 \pm 0.08$ \\
\hline Arabinose & $25.40 \pm 0.6^{a}$ & $8.49 \pm 0.02$ \\
\hline Galactose & $1.27 \pm 0.01$ & $2.14 \pm 0.03$ \\
\hline Glucose & $15.23 \pm 0.07$ & $177.84 \pm 1.09$ \\
\hline Xylose/Mannose & $0.88 \pm 0.02$ & $10.17 \pm 0.11$ \\
\hline Fructose & NA & $1.71 \pm 0.00$ \\
\hline Total & 42.78 & 205.71 \\
\hline
\end{tabular}

${ }^{a}$ Mean of three replicate analyses. NA: not applicable. 
Table 2 Chemical composition of termite-chewed and control sample.

\begin{tabular}{lll}
\hline & $\begin{array}{l}\text { Undigested softwood } \\
\text { (\%) }\end{array}$ & $\begin{array}{l}\text { Termite-chewed } \\
\text { softwood (\%) }\end{array}$ \\
\hline Glucose & $36.25 \pm 1.16^{\mathrm{a}}$ & $24.05 \pm 0.92$ \\
Galactose & $6.30 \pm 0.18$ & $5.85 \pm 0.20$ \\
Xylose/Mannose & $26.00 \pm 0.72$ & $16.99 \pm 0.63$ \\
$\begin{array}{l}\text { Acetyl bromide } \\
\text { lignin }\end{array}$ & $20.85 \pm 0.14$ & $22.81 \pm 0.09$ \\
$\begin{array}{l}\text { Acid insoluble } \\
\text { lignin }\end{array}$ & $18.13 \pm 0.82$ & $18.68 \pm 0.89$ \\
$\begin{array}{l}\text { Acid soluble } \\
\text { lignin }\end{array}$ & $2.62 \pm 0.18$ & $3.78 \pm 0.23$ \\
\hline
\end{tabular}

${ }^{a}$ Mean of three replicate analyses.

in the ball milled softwood control. Due to the limited cellulose substrate content in the chewed sample (Table 2 ), the hydrolysis rate slowed after 12 hours of hydrolysis and the enhancement in the release of C6 sugars was not maintained after 24 hours' hydrolysis. Meanwhile, the conversion ratio of cellulose in the termite-chewed softwood significantly increased compared with the control, which demonstrates that termite chewing enhances the release of cellulose. The conversion rates of hemicelluloses to C5 sugars are below 20\% for both the termitechewed and control samples because no specific hemicellulase was used for the hydrolysis. In comparison to the control, the termite-chewed softwood was less susceptible to the release and/or conversion of C5 sugars (Figure 1A, B), which is supported by the lower hemicellulose content (Table 2).

These results strongly indicate that the chewing process of softwood by termites has effectively acted upon the hemicellulosic counterpart and/or lignin-hemicellulose association, preferentially utilizing the $\mathrm{C} 5$ sugars by removal and degradation of the hemicellulose framework at the early digestion stage. During the termite chewing process, there are labial and/or salivary secretions, containing cellulases, hemicellulases and lignolytic enzymes, released on not only the chewed and liberated wood particles, but also the wood blocks. This erodes the softwood in a combined mechanical and enzymatic process for efficient initial pretreatment. This initial degradation also causes a more rapid drop in the strength properties of wood, which reflects holocellulose depolymerization.

\section{Pyrolysis gas chromatography mass spectrometry of monomeric lignin composition changes during the termite chewing process}

Pyrolysis produced partial degradation of the lignin side chains, but the aromatic-ring substituent (hydroxyl and methoxyl groups) remained intact, making it possible to identify products arising from the lignin units [26]. Py-GC/MS is a rapid and highly sensitive method for characterizing the chemical structure of lignin, allowing the analysis of a small sample without prior manipulation and isolation [27]. Although there is abundant information on the analytical pyrolysis of different wood types, reports on biologically modified wood are scarce $[28,29]$. In this study, Py-GC/MS provides qualitative information on in situ chemical structural changes of lignin subunits after termite chewing.

Pyrolysis of the softwood biomass yielded a wide range of products, of which the most characteristic are ligninrelated guaiacol derivatives, cellulose-related glucosan derivatives and hemicellulose-related furfural derivatives. In agreement with the information provided by the composition analysis and sugar release ability analysis, the increased lignin content (estimated from the total amount of lignin pyrolysis products) corresponded to the chewed softwood. Figures 2 and 3 and Table 3
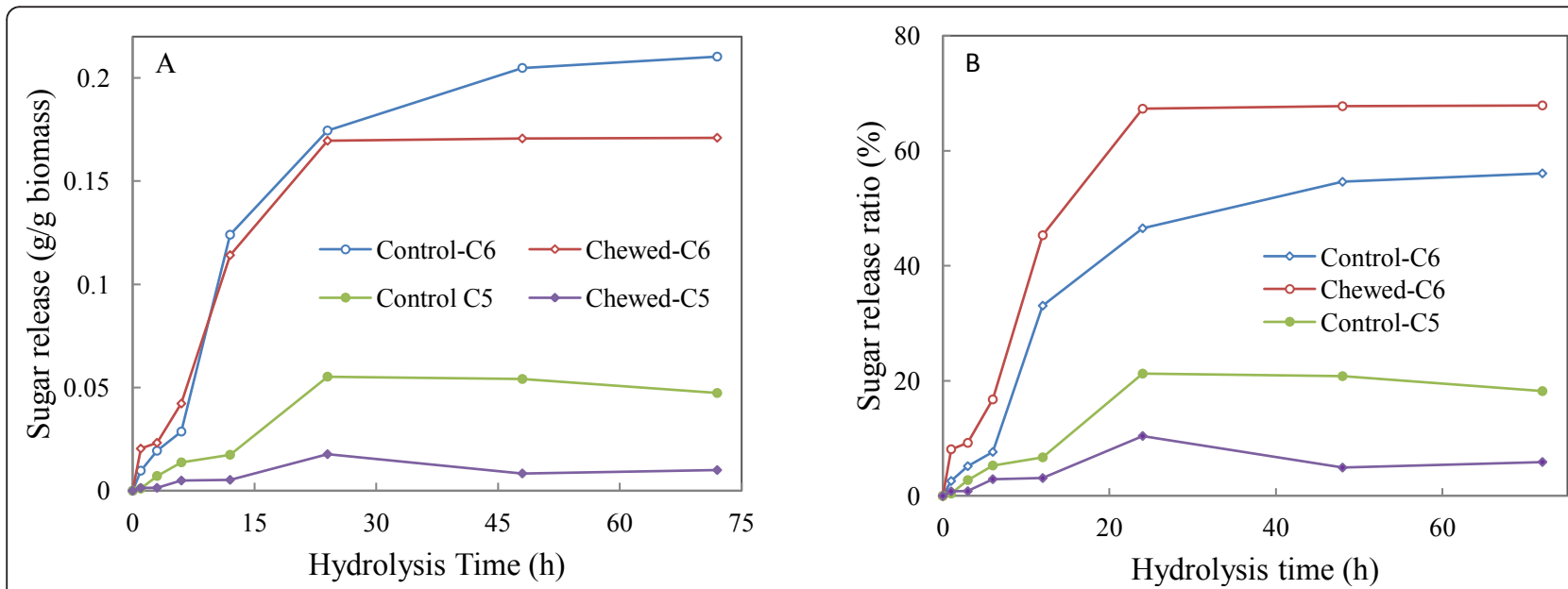

Figure 1 Influence of termite chewing on enzymatic release of C5 and C6 sugars from the softwood. (A) Amount of sugars released from per gram of softwood biomass. (B) Conversion ratio of cellulose and hemicelluloses. 


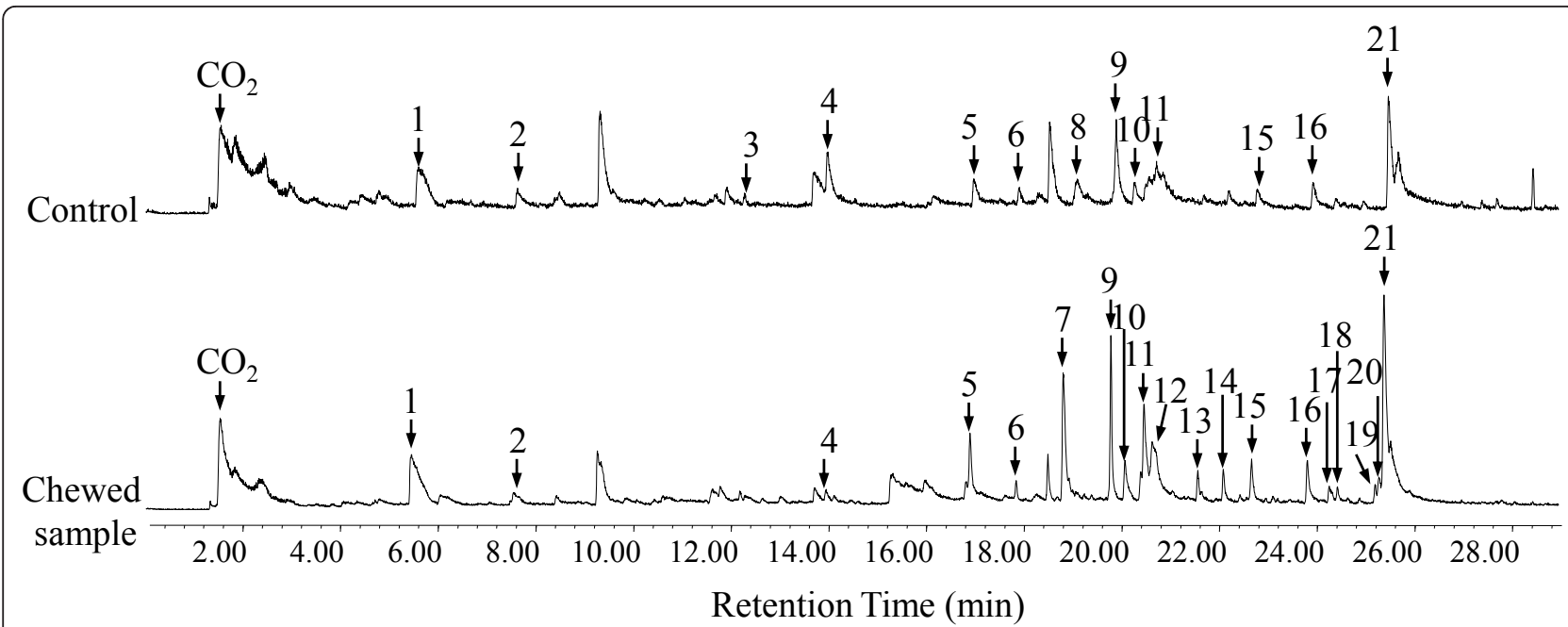

Figure 2 Pyrogram at $340^{\circ} \mathrm{C}$. Py-GC/MS spectra of termite-chewed softwood and undigested control at $340^{\circ} \mathrm{C}$. See the details of the labeled pyrolysates in Table 3 and Figure 3.

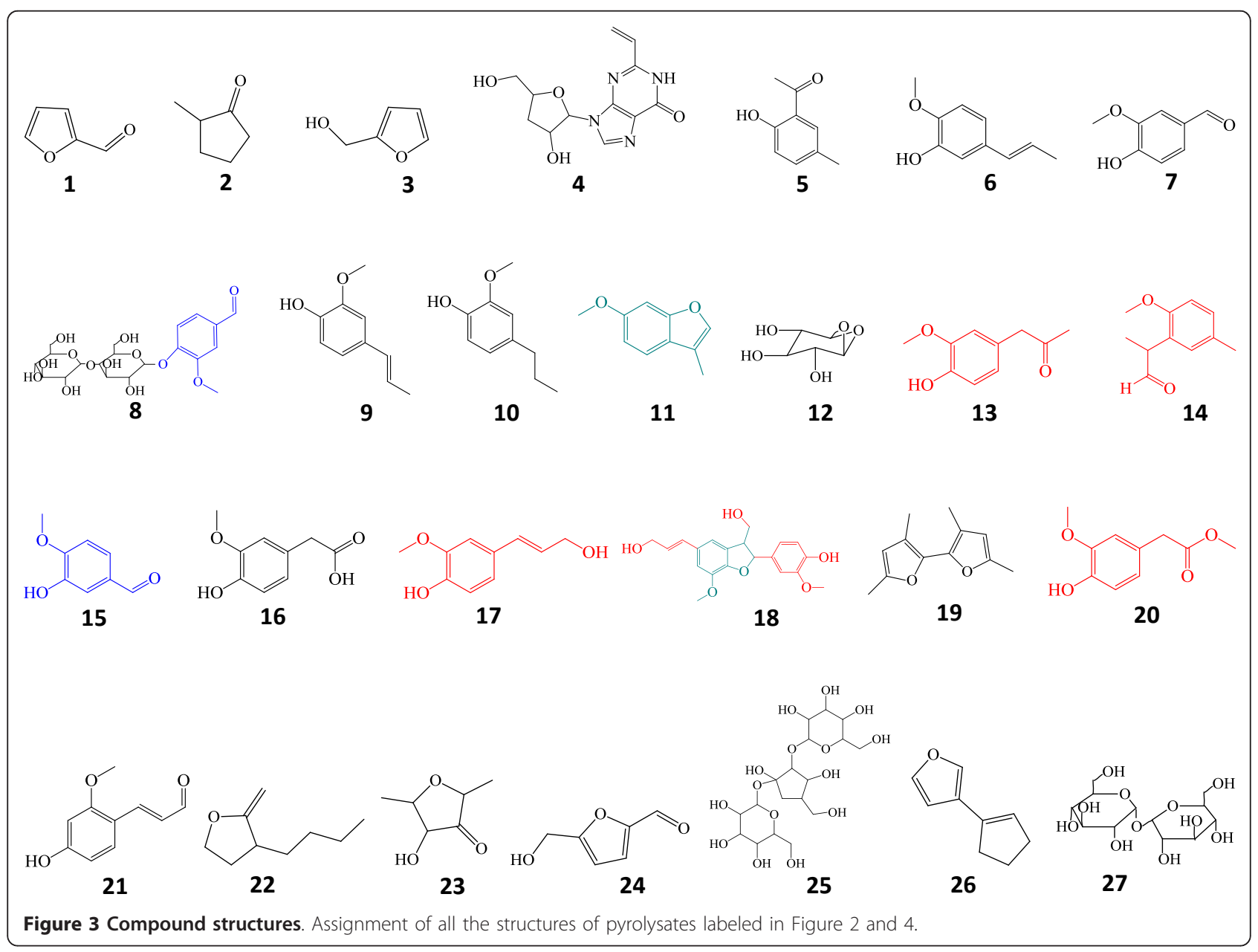


Table 3 Percentages of pyrolysis products from termite-chewed softwood and undigested control at $340^{\circ} \mathrm{C}$.

\begin{tabular}{|c|c|c|c|c|c|c|}
\hline & Name & $\begin{array}{l}\text { Molecular } \\
\text { formula }\end{array}$ & $\begin{array}{l}\text { Molecular } \\
\text { weight }\end{array}$ & $\begin{array}{l}\text { Retention } \\
\text { time (min) }\end{array}$ & $\begin{array}{l}\text { *Control }^{*} \text { (\%) } \\
\text { (\%) }\end{array}$ & $\begin{array}{l}\text { Chewed } \\
\text { softwood (\%) }\end{array}$ \\
\hline 1 & Furfural & $\mathrm{C} 5 \mathrm{H} 4 \mathrm{O} 2$ & 96 & 5.666 & 0.37 & 0.07 \\
\hline 2 & 2-methyl-cyclopentanone & $\mathrm{C} 6 \mathrm{H} 10 \mathrm{O}$ & 98 & 7.628 & 0.04 & 0.01 \\
\hline 3 & 2-furanmethanol & $\mathrm{C} 5 \mathrm{H} 6 \mathrm{O} 2$ & 98 & 12.257 & 0.03 & NA \\
\hline 4 & 2-vinyl-9-[3-deoxy- $\beta$-d-ribofuranosyl]hypoxanthine & $\mathrm{C} 12 \mathrm{H} 14 \mathrm{~N} 4 \mathrm{O} 4$ & 278 & 14.013 & 0.10 & 0.10 \\
\hline 5 & 1-(2-hydroxy-5-methylphenyl)-ethanone & $\mathrm{C} 9 \mathrm{H} 10 \mathrm{O} 2$ & 150 & 16.968 & 0.24 & 2.25 \\
\hline 6 & 2-methoxy-5-(1-propenyl)-,(E)-phenol & $\mathrm{C} 10 \mathrm{H} 12 \mathrm{O} 2$ & 164 & 17.917 & 0.20 & 0.23 \\
\hline 7 & Vanillin & $\mathrm{C} 8 \mathrm{H} 8 \mathrm{O} 3$ & 152 & 18.866 & NA & 4.09 \\
\hline 8 & Vanillin lactoside & $\mathrm{C} 2 \mathrm{OH} 28 \mathrm{O} 13$ & 476 & 19.164 & 0.23 & NA \\
\hline 9 & 2-methoxy-4-(1-propenyl)-(E)-phenol & $\mathrm{C} 10 \mathrm{H} 12 \mathrm{O} 2$ & 164 & 19.858 & 1.06 & 4.12 \\
\hline 10 & 2-methoxy-4-propyl-phenol & $\mathrm{C} 10 \mathrm{H} 14 \mathrm{O} 2$ & 166 & 20.126 & 0.18 & 1.83 \\
\hline 11 & 6-methoxy-3-methylbenzofuran & $\mathrm{C} 10 \mathrm{H} 10 \mathrm{O} 2$ & 162 & 20.45 & 0.33 & 4.26 \\
\hline 12 & Levoglucosan & $\mathrm{C} 6 \mathrm{H} 10 \mathrm{O} 5$ & 162 & 20.687 & NA & 2.08 \\
\hline 13 & 1-(4-hydroxy-3-methoxyphenyl)-2-propanone & $\mathrm{C} 10 \mathrm{H} 12 \mathrm{O} 3$ & 180 & 21.636 & NA & 0.61 \\
\hline 14 & 2-methoxy- $\alpha, 5$-dimethyl-benzeneacetaldehyde & $\mathrm{C} 11 \mathrm{H} 14 \mathrm{O} 2$ & 178 & 22.153 & NA & 0.93 \\
\hline 15 & 3-hydroxy-4-methoxy-benzaldehyde & $\mathrm{C} 8 \mathrm{H} 8 \mathrm{O} 3$ & 152 & 22.732 & 0.20 & 1.27 \\
\hline 16 & 4-hydroxy-3-methoxy-benzeneacetic acid & $\mathrm{C} 9 \mathrm{H} 10 \mathrm{O} 4$ & 182 & 23.866 & 0.30 & 1.18 \\
\hline 17 & 4-((1E)-3-hydroxy-1-propenyl)-2-methoxyphenol & $\mathrm{C} 10 \mathrm{H} 12 \mathrm{O} 3$ & 180 & 24.319 & NA & 0.12 \\
\hline 18 & $\begin{array}{l}\text { Methoxyphenyl)-5-(3-hydroxy-1-propenyl)-7- methoxy-2,3-dihydro-2- } \\
\text { (4-hydroxy-3-3-benzofuranmethanol }\end{array}$ & $\mathrm{C} 2 \mathrm{OH} 22 \mathrm{O} 6$ & 358 & 24.487 & NA & 0.20 \\
\hline 19 & 3,3',5,5'-tetramethyl-2,2'-bifuryl & $\mathrm{C} 12 \mathrm{H} 14 \mathrm{O} 2$ & 190 & 25.251 & NA & 0.27 \\
\hline 20 & Benzeneacetic acid, 4-hydroxy-3-methoxy-, methyl ester & $\mathrm{C} 10 \mathrm{H} 12 \mathrm{O} 4$ & 196 & 25.333 & NA & 0.29 \\
\hline 21 & 4-hydroxy-2-methoxycinnamaldehyde & $\mathrm{C} 10 \mathrm{H} 10 \mathrm{O} 3$ & 178 & 25.436 & 1.24 & 7.14 \\
\hline
\end{tabular}

See the structures of the labeled pyrolysates in Figure 3. NA: not applicable

demonstrate the compositional changes of the termitechewed softwood by pyrolysis at $340^{\circ} \mathrm{C}$. The related pyrolyzed lignin-derived compounds increased after the termite chewing, indicating initial degradation of lignocellulosic carbohydrates in the termite buccal cavity, as well as no obvious degradation of lignin. Also, the furfural derivatives from the hemicelluloses and glucosan derivatives from the cellulose in the chewed sample were significantly lower than those in the control sample; leaving the relative content of phenols greatly increased in the chewed sample. This specified the metabolism of hemicelluloses and cellulose during oral digestion by termites. Moreover, Py-GC/MS supported that the composition of the lignin-derived fraction from the termite orally digested softwood varied from that of the undigested control.

The pyrograms (Figure 2) show a series of products characteristic of pyrolysis of phenylpropanoid compounds in both termite-chewed and native softwood. The main pyrolyzed products in the undigested softwood are simple-structural lignin derivatives (peaks 5, 6, $9,10,11,15,16,21$ ), and there are new pyrolyzed lignin derivatives in the preliminarily digested sample, such as compounds $7,12,13,14,17,18,19,20$. The complex structure (peak 8) in the native softwood sample reveals the linkage of hemicellulose and lignin in the PCW; hence, its disappearance after termite chewing demonstrates termite-induced bond cleavage between holocellulose and lignin, which is supported by the increasing amount of pyrolyzed compound 15 in the chewed sample. The significant increase of the relative amount of pyrolysate 16 in the chewed sample suggests the generation of lignin carbonyl groups by the pretreatment process of termite chewing to decrease the competitive adsorption effect on cellulases, since an increase in the carboxylic content of the lignin preparation is reported to result in an increased yield of cellulose hydrolysis [30]. The newly appearing pyrolyzed compounds (peaks 12 and 19) in the chewed sample at a low pyrolysis temperature indicate depolymerization and degradation of both cellulose and hemicellulose. New compounds of $13,14,17,18$, and 20 pyrolyzed from the termite-chewed sample demonstrate the modification of lignin after oral digestion. The appearance of pyrolysate 14 from chewed softwood refers to the dehydroxylation of the phenolic hydroxyl group. This functional group change is considered to remove the inhibitory effect of lignin since phenolic hydroxyl groups have been reported to exhibit critical inhibitory effects on cellulytic enzymes [31]. Compound 18 should be a small fragment pyrolyzed from the lignin molecular with phenylcoumaran $\left(\beta-5^{\prime}\right)$ substructure; its appearance only in the chewed sample can be attributed to the specific bond cleavage of the inter-unit linkage of lignin. 


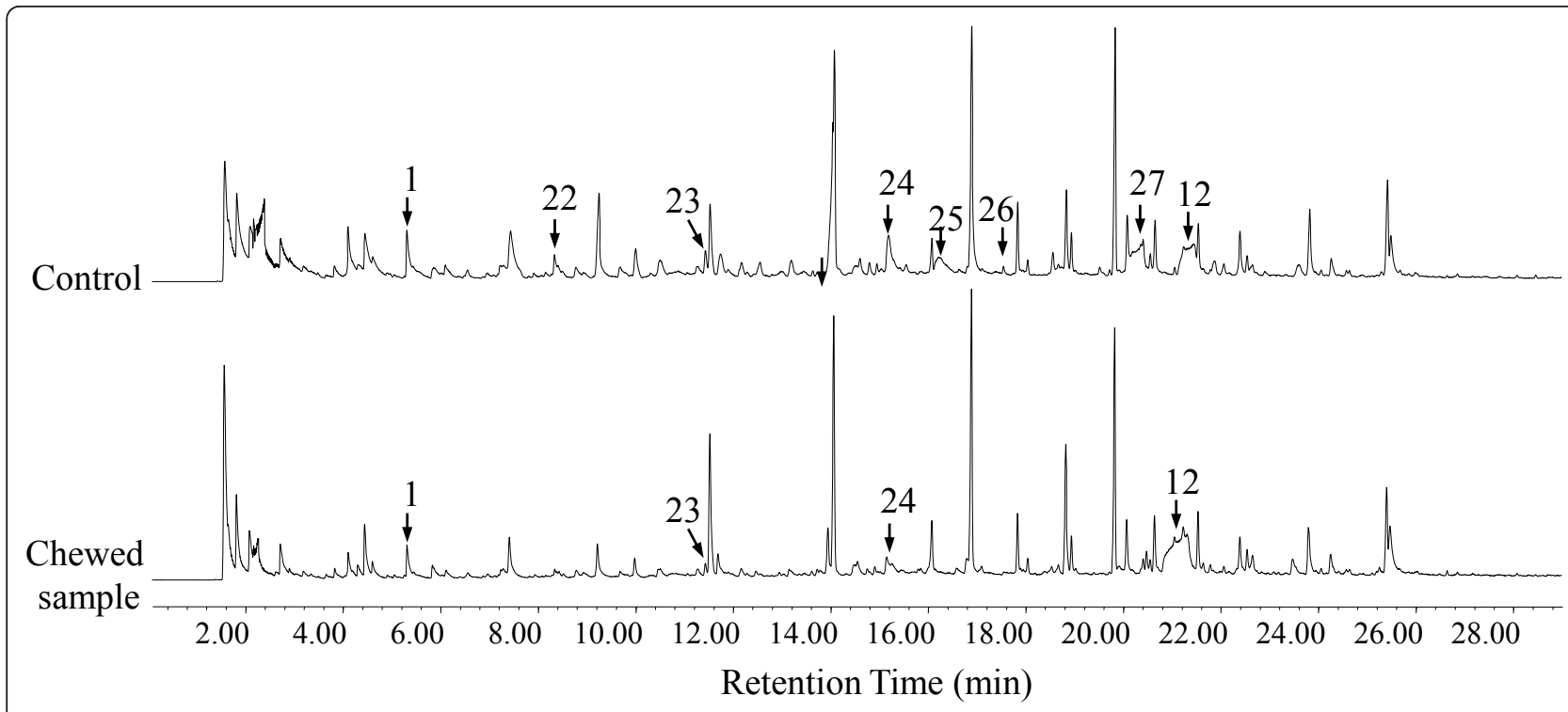

Figure 4 Pyrogram at $510^{\circ} \mathrm{C}$. Py-GC/MS spectra of termite-chewed softwood and undigested control at $510^{\circ} \mathrm{C}$. See the details of the labeled pyrolysates in Table 4 and Figure 3.

Then pyrolysis was performed at a temperature of $510^{\circ} \mathrm{C}$ (Figures 3, 4 and Table 4) for termite feces and undigested control; the lignin derivatives were released at approximately the same amount for the two samples, indicating no further degradation in the lignin structure by termite. Since a high temperature will be more effective in the cleavage of bonds with high dissociation energy, even if there is lignin modification it is hard to be reflected in the high temperature pyrolysis pyrogram. During high temperature pyrolysis, the cellulose and hemicellulose becomes more easily pyrolyzed into small molecule volatiles; however, there still are some complex structure coming out (peak 25) due to protection by the cell wall lignin. Disappearance of compound 25 in the chewed sample indicates that cleavage occurs between the cellulose and hemicellulose molecules. Disappearance of pyrolytic compounds 22, 26 and 27, as well as the decrease of compounds 23 and 24, in the termitechewed sample indicate degradation and modification of hemicelluloses and cellulose.

\section{Attenuated total reflectance Fourier transform infrared spectroscopic analysis of functional group changes during termite chewing process}

The FTIR spectra of termite-chewed softwood and the undigested control are shown on Figure 5. Table 5 lists the main assignments of the functional groups in FTIR bands. ATR-FTIR analysis of the lignin from the undigested wood sample showed spectra dominated by aromatic ring vibration and $\mathrm{C}=\mathrm{O}$ bonds (peaks 4 and 6 ) [32]. The spectrum of the termite-chewed sample showed higher intensity peaks, indicating the exposure and more vibration of aromatic rings (also supported by decreases in peaks 14 and 17) and the $\mathrm{C}=\mathrm{O}$ bond (also

Table 4 Percentages of pyrolysates from termite-chewed and control sample at $510^{\circ} \mathrm{C}$.

\begin{tabular}{|c|c|c|c|c|c|c|}
\hline & Name & $\begin{array}{l}\text { Molecular } \\
\text { formula }\end{array}$ & $\begin{array}{l}\text { Molecular } \\
\text { weight }\end{array}$ & $\begin{array}{l}\text { Retention time } \\
(\mathrm{min})\end{array}$ & $\begin{array}{l}\text { Control }^{a} \\
(\%)\end{array}$ & $\begin{array}{l}\text { Chewed } \\
\text { softwood (\%) }\end{array}$ \\
\hline 1 & Furfural & $\mathrm{C} 5 \mathrm{H} 4 \mathrm{O} 2$ & 96 & 5.324 & 1.21 & 0.88 \\
\hline 22 & 3-butyldihydro-2(3H)-furanone & $\mathrm{C} 8 \mathrm{H} 14 \mathrm{O} 2$ & 142 & 8.340 & 0.50 & NA \\
\hline 23 & 2,5-dimethyl-4-hydroxy-3(2H)-furanone & $\mathrm{C} 6 \mathrm{H} 8 \mathrm{O} 3$ & 128 & 11.442 & 0.57 & 0.26 \\
\hline 24 & 5-(hydroxymethyl)-2-furancarboxaldehyde & $\mathrm{C} 6 \mathrm{H} 6 \mathrm{O} 3$ & 126 & 15.191 & 1.96 & 0.37 \\
\hline $25^{\mathrm{b}}$ & $\begin{array}{l}\alpha \text {-D-glucopyranoside, O- } \alpha \text {-D-glucopyranosyl-(1.fwdarw.3)- } \beta \text { - } \\
\text { D-fructofuranosyl }\end{array}$ & $\mathrm{C} 18 \mathrm{H} 32 \mathrm{O} 16$ & 504 & 16.226 & 1.49 & NA \\
\hline $26^{c}$ & 3-(1-cyclopentenyl) furan & $\mathrm{C} 9 \mathrm{H} 10 \mathrm{O}$ & 134 & 17.555 & 0.12 & NA \\
\hline 27 & $\alpha$-D-glucopyranoside, $\alpha$-D-glucopyranosyl & $\mathrm{C} 12 \mathrm{H} 22 \mathrm{O} 11$ & 342 & $20.182-20.432$ & 3.02 & NA \\
\hline $12^{\mathrm{d}}$ & Levoglucosan & $\mathrm{C} 6 \mathrm{H} 10 \mathrm{O} 5$ & 162 & $21.200-21.511$ & 4.33 & 9.02 \\
\hline
\end{tabular}

${ }^{a}$ Mean of three replicate analyses; ${ }^{b}$ cleavage between cellulose and hemicelluloses molecules; ${ }^{c}$ prefer degradation of hemicelluloses units; ${ }^{d}$ probable depolymerization of the cellulose fiber. See the structures of the labeled pyrolysates in Figure 3. 


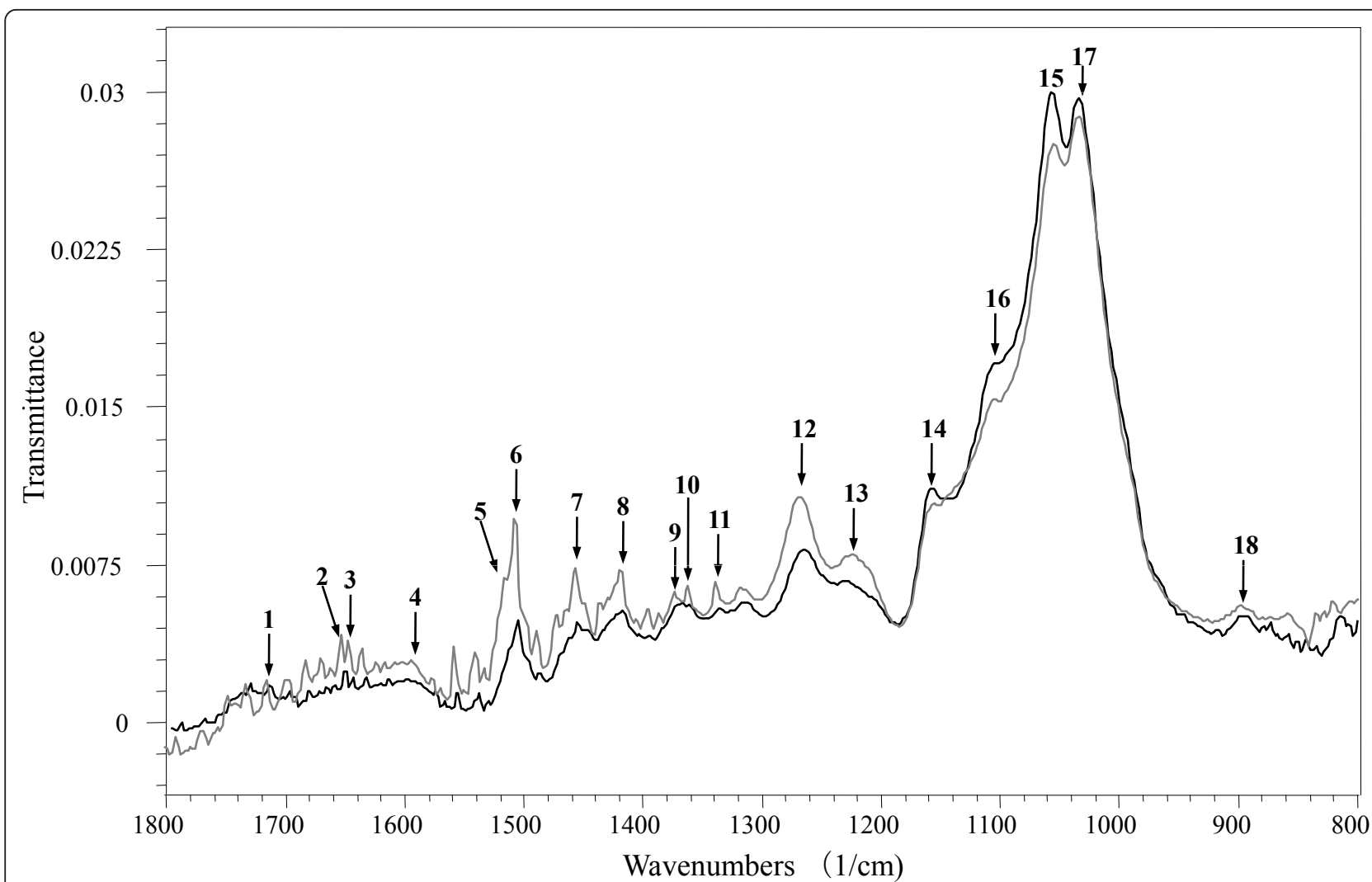

Figure 5 Spectroscopy. Selected FTIR spectra, 1800 to $800 \mathrm{~cm}^{-1}$ region, for functional group changes after termite chewing. Black: undigested softwood control; grey: termite-chewed sample. See Table 5 for assignment of FTIR signals.

Table 5 Main assignments of lignin, polysaccharide and protein Fourier transform infrared bands. ${ }^{a}$

\begin{tabular}{|c|c|c|}
\hline & Wavenumbers $\left(\mathrm{cm}^{-1}\right)$ & Assignments \\
\hline \multicolumn{3}{|c|}{ Lignin } \\
\hline 1 & 1714 to 1725 & Stretching of $\mathrm{C}=\mathrm{O}$ unconjugated to aromatic rings (oxidized side-chains) \\
\hline 3 & 1655 & Stretching of $\mathrm{C}=\mathrm{O}$ conjugated to aromatic rings \\
\hline 4 & 1594 to 1609 & Aromatic ring vibrations and $\mathrm{C}=\mathrm{O}$ stretching \\
\hline 6 & 1504 to 1515 & Aromatic ring vibrations \\
\hline 7 & 1462 to 1464 & Asymmetric $\mathrm{C}-\mathrm{H}$ bending (in $\mathrm{CH}_{3}$ and $-\mathrm{CH}_{2}-$ ) \\
\hline 8 & 1421 to 1424 & Aromatic ring vibrations \\
\hline 10 & 1365 & Symmetric deformation of $\mathrm{C}-\mathrm{H}$ in methyl groups \\
\hline 11 & 1360 & Phenolic hydroxyl vibrations \\
\hline 12 & 1270 (shoulder) & Vibrations of guaiacyl rings and stretching vibrations of $\mathrm{C}-\mathrm{O}$ bonds \\
\hline 13 & 1216 to 1225 & $\mathrm{C}-\mathrm{C}, \mathrm{C}-\mathrm{O}$ and $\mathrm{C}=\mathrm{O}$ stretching ( $\mathrm{G}$ condensed $>\mathrm{G}$ etherified) \\
\hline 14 & 1160 & Deformation vibrations of $\mathrm{C}-\mathrm{H}$ bonds on benzene rings \\
\hline 16 & 1090 to 1075 & Deformation vibrations of C-O bonds in secondary alcohols and aliphatic ethers \\
\hline 17 & 1030 to 1033 & Deformation vibrations of $\mathrm{C}-\mathrm{H}$ bonds in aromatic rings \\
\hline \multicolumn{3}{|c|}{ Polysaccharide } \\
\hline 9 & 1370 & Symmetric bending of aliphatic $\mathrm{C}-\mathrm{H}$ \\
\hline 15 & 1030 to 1170 & $\mathrm{C}-\mathrm{O}$ stretching in alcohols \\
\hline 18 & 890 & $\beta$-Glycosidic linkages in pyranose units \\
\hline \multicolumn{3}{|c|}{ Protein } \\
\hline 2 & 1655 to 1658 & $\mathrm{C}=\mathrm{O}$ stretching in amides $(\mathrm{I})$ \\
\hline 5 & 1516 & $\mathrm{C}=\mathrm{O}$ stretching in amides $(\mathrm{II})$ \\
\hline
\end{tabular}

${ }^{\text {a }}$ Referred to references 32 to 34 . 
supported by peaks 1 and 3) [32-34]. The increasing intensity of peak 7 and 10 of the chewed sample can be attributed to the metabolism of $-\mathrm{CH}_{3}$ and $-\mathrm{CH}_{2}$ groups. It is speculated that the removal of methyl group will help to alleviate the steric hindrance effect of lignin to cellulytic enzymes. In addition, the lignin hydroxyl group was also modified (peak 11), which supports the previous Py-GC/MS data on possible phenolic dehydroxylation (Figures 2 and 4) for the removal of the lignin inhibitory effect. Interestingly, the most obvious change was observed in the range of 1300 to $1600 \mathrm{~cm}^{-1}$, indicating greater exposure of the guaiacyl rings and $\mathrm{C}$ $\mathrm{O}$ bonds (peak 12), as well as esterification of $-\mathrm{OCH}_{3}$ groups (peak 13) [34]. Here, greater exposure of aromatic rings and $\mathrm{C}-\mathrm{O}$ bonds might be attributed to the lignin side-chain modification; together with phenolic methoxyl group modification, it may help with downstream hydrolysis by alleviating steric hindrance effects of lignin. Meanwhile, the shape change of peak 16 may be attributed to the deformation vibrations of $\mathrm{C}-\mathrm{O}$ bonds in secondary alcohols and aliphatic ethers, and vibrations of ester linkages on lignin side chains. Increasing intensity of peak 9 and decreasing intensity of peaks 15 and 18 of the chewed sample indicated more bending of aliphatic $\mathrm{C}-\mathrm{H}$, as well as less polysaccharide content there (Table 5) [32-34]. Greater intensities of both the peaks 2 and 5 suggest the existence of proteins in the chewed sample, which were assumed to be digestion enzymes from termite saliva and labial gland secretion.

In summary, the FTIR data showed that, to alleviate the lignin inhibitory effect, the termite oral digestion might have induced exposure and destruction of the aromatic ring; cleavage of bonds $\mathrm{C}=\mathrm{O}, \mathrm{C}-\mathrm{H}, \mathrm{O}-\mathrm{H}$ and $\mathrm{C}-\mathrm{O}$ in lignin methoxyl groups, secondary alcohols and aliphatic ethers; deformation of the lignolytic $\mathrm{C}-\mathrm{H}$ bond in $-\mathrm{CH}_{3}$ and $-\mathrm{CH}_{2}$ groups; initial degradation of polysaccharide; and secretion of proteins during this process.

\section{Thermogravimetry analysis for thermal stability of termite-chewed softwood}

The TG/DTG curves of termite-chewed softwood and native control are shown in Figure 6. This analysis was done to investigate the changes of thermal degradation kinetics of softwood after termite chewing. Wood decomposition commences at around $200^{\circ} \mathrm{C}$ with the decomposition of lignin and hemicellulose moieties, while the decomposition of the xylan component takes place at around $300^{\circ} \mathrm{C}$ [35]. The shoulder on the DTG curve of undigested wood represents the xylan present (Figure 6). The highest DTG peak of the undigested wood spectrum at around $360^{\circ} \mathrm{C}$ corresponds to the decomposition of cellulose [36].

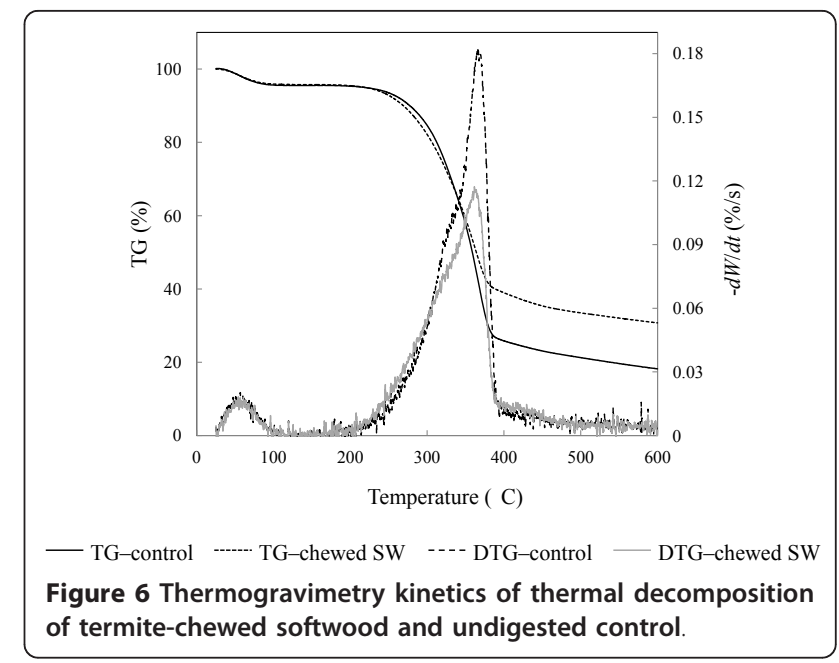

While comparing the thermal decomposition behavior of the termite-chewed softwood to the undigested control, the DTG curve clearly showed large fluctuations during decomposition of the biomass. Chewed biomass decomposition began earlier and the maximum rate shifted left compared to the softwood control, indicating that a lower temperature is capable of converting the chewed sample to volatiles (Figure 6). The lowering of initiation temperature corresponds to a decrease in minimum energy required to start the active gasification reaction in the chewed wood. Meanwhile, the maximum rate of thermal decomposition of the chewed sample largely decreased, showing low cellulose and/or hemicellulose content that also was demonstrated by Py-GC/MS.

Lignin decomposition usually occurs over a wide temperature range, which has pronounced temperature maxima up to $900^{\circ} \mathrm{C}[37,38]$. The starting point for termite-chewed softwood on the DTG curve (Figure 6) shifted to the left and increased pyrolysis rate from $200^{\circ}$ $\mathrm{C}$ to $300^{\circ} \mathrm{C}$, thereby indicating a rapid decomposition of the chewed wood particles. Lignin side chain oxidation with production of more carbonyl groups in the chewed sample (Figure 4) might be one of the contributing factors for the initial thermal degradation stage [39], which was also demonstrated by Py-GC/MS. On the other hand, the TG curves showed a larger residual amount of biomass in termite-chewed wood at a high temperature between 400 and $600^{\circ} \mathrm{C}$ in comparison to the undigested sample. A possible explanation is that once lignin was modified, part of its intermediate fragments will be rearranged through condensation and re-polymerization [40], leading to new structures with more stability. Such rearrangement might either occur during the chewing process in termites or possibly in the pyrolysis process.

By employing the model as described in the method section, the acquired activation energies and pre- 
exponential factors at different temperature stages will help reveal the chemical structure of biomass components [41]. Table 6 shows that, during the low temperature pyrolysis $\left(220\right.$ to $\left.376^{\circ} \mathrm{C}\right)$, the activation energy decreased after termite chewing, while the pre-exponential factor increased. This could be attributed to the degradation of carbohydrates and modification of lignin, leading to more exposure and reactivity of the carbohydrate. The participation of more modified thermalunstable lignin in this pyrolysis step, as indicated by the shift of the DTG-chewed sample curve to a lower temperature in Figure 6, may contribute to the decrease of the activation energy in this temperature range. At a pyrolysis temperature of 376 to $539^{\circ} \mathrm{C}$, the activation energy of the softwood biomass significantly increased after termite chewing, indicating that within this temperature range the residual lignin for pyrolysis should have been rearranged and was more stable than the undigested control. This can be explained as a result of lignin functional group modification and/or lignolytic molecules contributing towards increased stabilization of the residual lignin structure by rearrangement. The pre-exponential factor of termite-chewed wood increased at this stage, indicating the necessity of a higher rate of molecular collisions for the rearranged lignin component of the termite digested sample. At the highest temperature $\left(539\right.$ to $595^{\circ} \mathrm{C}$ ) pyrolysis stage, the activation energy of the termite-chewed sample decreased, together with an increase of the pre-exponential factor. The decomposition of lignin occurred within a wide temperature range [41], indicating that the remaining lignin structure, which is thermally intractable, was more reactive than the undigested control after termite chewing, which is speculated to be relevant to the cleavage of stable ether bonds (that is, 5-5, [42]) within the lignin network and redistribution of lignin functional groups in the chewed plant tissue. This further supported the previous Py-GC/MS data.

Although the PCW deconstruction process in termite gut is well established [4-6,43], there have been no

\begin{tabular}{|c|c|c|c|c|}
\hline Temperature $\left({ }^{\circ} \mathrm{C}\right)$ & Samples & $E\left(\mathrm{~kJ} \mathrm{~mol}^{-1}\right)$ & $A\left(\mathrm{~s}^{-1}\right)$ & $\mathrm{R}\left(\mathrm{Jmol}^{-1} \mathrm{~K}^{-1}\right)$ \\
\hline \multirow[t]{2}{*}{220 to 376} & Control & 48.99 & $4.09 \times 10^{4}$ & 0.9647 \\
\hline & Chewed & 46.73 & $4.98 \times 10^{4}$ & 0.9861 \\
\hline \multirow[t]{2}{*}{376 to 539} & Control & 2.76 & $6.48 \times 10^{6}$ & 0.9654 \\
\hline & Chewed & 6.02 & $8.68 \times 10^{6}$ & 0.9908 \\
\hline \multirow[t]{2}{*}{539 to 595} & Control & 35.16 & $7.11 \times 10^{5}$ & 0.9474 \\
\hline & Chewed & 34.67 & $7.41 \times 10^{5}$ & 0.9473 \\
\hline
\end{tabular}

A: pre-exponential or frequency factor; $E$ : activation energy; R: gas constant. studies on the initial lignin pretreatment effect during the chewing. Moreover, earlier reports speculate that lignin deconstruction is initiated in the gut; however, they have not identified the specific site(s) [44]. Overall, this study demonstrated an enhanced conversion ratio of cellulose after a combined mechanical and enzymatic pretreatment during termite oral digestion. Associated utilization of holocellulosic counterparts and an increase of hydrolysable lignin in the PCW after termite chewing were also evident. In line with our earlier studies on lignin destruction in the termite gut $[5,6]$, the chewing process contributes to the overall lignin modification by initiating the pretreatment at an early stage for timesaving. Enzymes, such as laccase and phenoloxidase [18], released from the salivary glands and labial glands into the oral cavity during this stage should attach to the lignin substrate and function persistently during the passage of the wood diet through the gut. The main chemical reactions occurring during this stage are dehydroxylation of phenolic hydroxyl groups, side-chain oxidation and $\beta-5$ ' substructure modification. These reactions together with additive ring demethoxylation, end-unit cleavage and $\beta-\beta$ ' substructure modification further happened within the gut for a stepwise lignin disintegrate $[5,6]$. Results in this study support that modification of lignin structures occurs without degradation in any significant scale during termite chewing. In this regard, due to greater exposure of its polymeric network, modification of lignin are mainly associated with functional group changes and bond cleavage, possibly by depolymerization. These activities indicate the required participation of lignin-related enzyme(s) and/or polypeptide(s) and/or esterase during termite chewing behavior for the initial pretreatment on biomass. Also, the decrease of cellulose and hemicelluloses in the chewed sample infers the involvement of cellulases and hemicellulases in this process. All the results suggest that the PCW deconstruction process starts within the oral cavity of this termite species. The process involves not only mechanical grinding for particle size reduction and amorphous cellulose breakdown but also selective biochemical pretreatment of lignin, which makes this process more unusual in the approach to pretreatment of biomass (Figure 7). This reveals the advantages of the $C$. formosanus termite over white-rot fungi and other lignocellulosic-degrading microbes, in that it works as a highly efficient continuous and well-integrated system for ligninhemicellulose matrix deconstruction. Not all the lower termite species have this pre-digestion process; it is absent in several termite species [45]. This efficient wood degrader provides us with new information for improving pretreatment of lignocellulosics by providing the scientific base for integrating mechanical grinding and enzymatic lignin modification. 


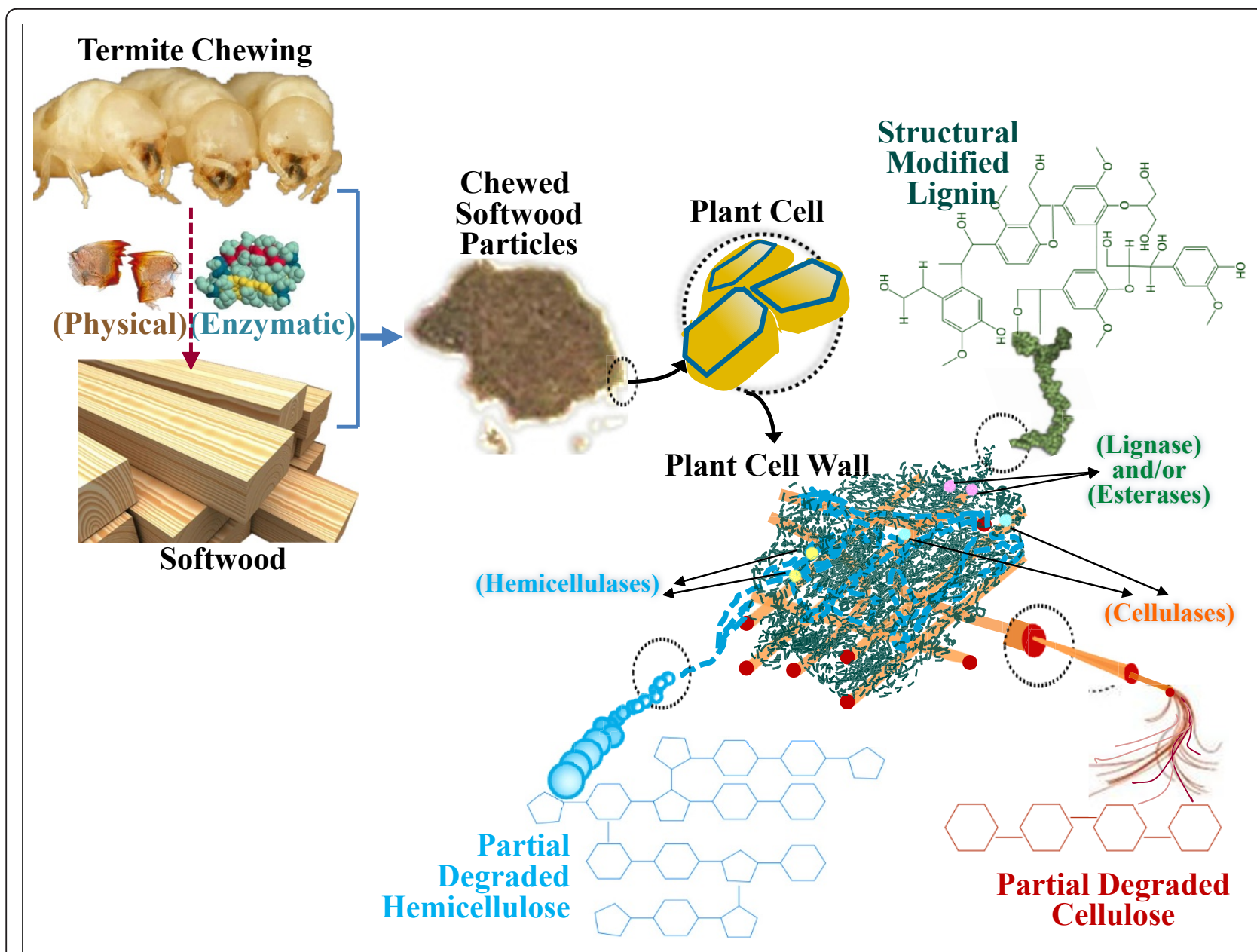

Figure $7 \mathrm{~A}$ proposed biomass destruction process during the termite-chewing process.

\section{Conclusions}

The termite chewing process induced selective pretreatment on the lignin counterpart and/or lignin-hemicellulose association. Consequently, the structural modification within the lignin matrix during the chewing process resulted in better exposure of the carbohydrate component within the PCW. These results could significantly contribute towards the current understanding of specific unlocking modification on lignin structure by the lower termites for efficient cellulose utilization, as well as promoting the existing biomass pretreatment technology for effective disintegration of the PCW structure to produce bioenergy-derived products and fuels. Combining the achievements of nature with those of mankind should lead to new breakthroughs in science and technology that are critical for converting lignocelluloses to biofuels.

\section{Methods}

\section{Termite cultivation and sample preparation}

Five hundred C. formosanus termite workers, which are responsible for feeding in the colony, were collected in
Poplarville, Mississippi, and starved at $28^{\circ} \mathrm{C}$ and $90 \%$ humidity for 40 hours to try to evacuate their alimentary canals. Termite digestion is thought to be accomplished within 24 hours [46-48], and the gut evacuation was supported by the Py-GC/MS results in Additional file 1 with no evidence of lignolytic, cellulosic or hemicellulosic pyrolysate in the pyrogram, thus no feces should have been contained in the chewed sample collected.

The termites were provided with $6.8 \times 1.5 \times 0.5$ inch blocks of Southern pine (Pinus australis F. Michx) and left for 15 hours at $28^{\circ} \mathrm{C}$ and $90 \%$ humidity. Termitechewed softwood particles were collected from the corner of the container, avoiding those in contact with the wood blocks. The lignin in this species of pine consists almost exclusively of guaiacyl propane subunits [49]. The experimental conditions ( 40 hours of starvation followed by 15 hours of wood-feeding) were repeated several times for different groups of termite workers for sample collection. The particle size of the chewed softwood was approximately $50 \mu \mathrm{m}$ as estimated under the microscope. The undigested softwood tissues were ball 
milled to the same particle size, and used as control samples. The effect of this starvation treatment on enzyme secretion of termite workers was ignored since short-term starvation, and even the long-term starvation, does not lead to complete loss of enzyme secretion $[50,51]$, and wood provision after 40 hours will help termite workers re-acquire their normal level of enzyme production [42]. However, we need keep in mind of the probable lowered secretion of cellulases and lignases from the salivary glands.

\section{Washing-up of termite-chewed particles for free sugars}

The termite-chewed softwood particles, in 100-mg batches, and the same weight of control softwood were individually soaked in $400-\mu \mathrm{L}$ deionized water and stirred for 6 hours at room temperature. Sugar concentrations in the resulting extracts were determined by the Dionex ion chromatograph (IC). The extractives were filtered through a $0.45-\mathrm{mm}$ filter prior to sample analysis. Sugars were separated on CarboPac PA 20 Guard (4 $\times 50 \mathrm{~mm})$ and analytical columns $(4 \times 250 \mathrm{~mm})$ at room temperature $\left(25^{\circ} \mathrm{C}\right)$. Sugar detection was by an ED40 electrochemical detector (Dionext Corp., Bannockburn, IL, USA). An AS40 sampler (Dionext Corp.) was used for continuous running and Dionex PeakNet 5.1 chromatography software was used for data analysis.

\section{Wood composition analysis}

For analysis of the acetyl bromide lignin content, both the control and termite-chewed softwood tissues (200 $\mathrm{mg}$ ) were individually frozen in liquid nitrogen. Extractive-free freeze-dried CWRs were prepared as described previously [25] and then subjected to acetyl bromide analysis $[52,53]$. The lignin contents of extractive-free CWRs samples for both the control and termite-chewed softwood tissues were estimated in terms of percentage weight of the extractive-free freeze-dried CWRs.

For a further chemical composition analysis, $1 \mathrm{~mL}$ $72 \%$ sulfuric acid was added into $100 \mathrm{mg}$ of each freezedried extractive-free sample separately and incubated in a $30^{\circ} \mathrm{C}$ water bath for 1 hour. Then, $29 \mathrm{~mL}$ deionized water was added into each sample separately, and the two samples were placed in an autoclave (Brinkmann 2540 M, Tuttnauer USA CO. Ltd, Hauppauge, NY, USA) at $121^{\circ} \mathrm{C}$ for 1 hour, then the water loss was supplemented. After centrifugation, the supernatant was diluted and subjected to the Dionex IC and UV spectroscopy with absorbance at $205 \mathrm{~nm}(0.2$ to 0.7$)$ with an extinction coefficient of $110 \mathrm{~L} \mathrm{~g}^{-1} \mathrm{~cm}^{-1}$ for analysis of contents of sugars and acid soluble lignin [54]. The solid phase was washed three times with deionized water and finally freeze-dried to obtain the acid insoluble lignin.

\section{Enzymatic hydrolysis of the termite-chewed wood particles}

Enzymatic hydrolysis of both the washed termite-chewed and control samples was carried out at $2 \%$ of solid component $(\mathrm{w} / \mathrm{v})$ in $10 \mathrm{~mL}$ sodium citrate buffer using a rotary shaker at $150 \mathrm{rpm}$. The $\mathrm{pH}$ and temperature were adjusted to 4.8 and $50^{\circ} \mathrm{C}$, respectively. A mixture of Celluclast 1.5 L (Sigma-Aldrich, Inc., St. Louis, MO, USA) and Novozyme 188 (Sigma-Aldrich, Inc.) with activity loadings of 60 filter paper units and 64 cellobiase units, respectively, as well as $3.2 \times 10^{-4}$ g sodium azide was used for enzymatic hydrolysis per one gram of substrate. Reaction mixtures were pre-incubated for $30 \mathrm{~min}$ prior to the addition of enzymes. Hydrolysates were sampled periodically $(1,3,6,12,24,48,72 \mathrm{~h})$ for sugar analysis. Each data point was averaged from three replicates.

Sugar concentrations in the hydrolysates were determined with IC. The hydrolysates were filtered through a $0.45 \mathrm{~mm}$ filter prior to sample analysis. Sugars were separated on CarboPac PA 20 Guard $(4 \times 50 \mathrm{~mm})$ and analytical columns $(4 \times 250 \mathrm{~mm})$ at room temperature $\left(25^{\circ} \mathrm{C}\right)$, and detected by an ED40 electrochemical detector. An AS40 sampler was used for continuous running and Dionex PeakNet 5.1 chromatography software was used for data analysis.

\section{Pyrolysis gas chromatography mass spectrometry analysis at $340^{\circ} \mathrm{C}$ and $510^{\circ} \mathrm{C}$}

Samples were frozen in liquid nitrogen to quench lignin digestion, and then loaded directly into a quartz tube (sample tube). For each sample tube, there was an approximately $10 \mathrm{mg}$ sample. The pyrolysis processes were performed with a CDS 5000 pyrolysis autosampler (Analytical, Inc., Oxford, PA, USA) attached to a Thermo Trace GC 6890N/MSD 5975B gas chromatography mass spectrometry system (Agilent Technologies, Inc., Bellevue, WA, USA). The wood samples were first pretreated at $210^{\circ} \mathrm{C}$ for $3 \mathrm{~min}$, and then pyrolyzed at a temperature of $340^{\circ} \mathrm{C}$ and $510^{\circ} \mathrm{C}$ for $1 \mathrm{~min}$, respectively. The sample of two guts of starved termites was first pretreated at $210^{\circ} \mathrm{C}$ for $3 \mathrm{~min}$, and then directly pyrolyzed at a temperature of $510^{\circ} \mathrm{C}$ for $1 \mathrm{~min}$. Finally the volatile products were held in the pyrolysis zone for $56 \mathrm{~min}$, separated on a $30 \mathrm{~m} \times 0.25 \mu \mathrm{m}$ inner diameter $(5 \%$ phenyl)-methylpolysiloxane column with helium 4.6 as carrier gas $\left(17.3 \mathrm{~mL} \mathrm{~min}{ }^{-1}\right)$ and identified by interpretation of their electron impact mass spectra in comparison to a NIST Mass Spectral Search 2.0 electronic library. The pyrolysis interface was kept at $210^{\circ} \mathrm{C}$ and the $\mathrm{GC} / \mathrm{MS}$ interface at $280^{\circ} \mathrm{C}$; the $\mathrm{GC} / \mathrm{MS}$ was programmed from $40^{\circ} \mathrm{C}(1 \mathrm{~min})$ to $280^{\circ} \mathrm{C}(15 \mathrm{~min})$ at a rate of $6^{\circ} \mathrm{C} \mathrm{min}^{-1}$. The mass spectrometer was operated in electron impact mode $(70 \mathrm{eV})$ at a source temperature of $230^{\circ} \mathrm{C}$. 


\section{Attenuated total reflectance Fourier transform infrared spectroscopic analysis}

To directly correlate the modification of lignin functional groups with the termite chewing process, ATR-FTIR spectra $\left(4500\right.$ to $\left.800 \mathrm{~cm}^{-1}\right)$ of both the termite-chewed and undigested softwood particles were obtained with a SHIMADZU IRPrestige-21 Fourier transform infrared Spectrophotometer (Shimadzu Corp., Kyoto, Japan) using approximately $2 \mathrm{mg}$ of each sample. A MIRacle ATR accessory with a high-pressure clamp (PIKE Technologies, Madison, WI, USA) was used. Spectra were obtained using the triangular apodization, a resolution of $4 \mathrm{~cm}^{-1}$ and an interval of $1 \mathrm{~cm}^{-1}$. Sixty-four scans were conducted for each background and sample spectra. Baseline and ATR corrections for penetration depth and frequency variations were applied using the Shimadzu IR solution 1.30 software supplied with the equipment.

\section{Thermogravimetric analysis}

TG/DTG analysis is based on the precise study of weight loss during programmed exposure to over a range of temperatures, to determine termite-induced changes in the general characteristics of lignocellulose decomposition and activation energies for bond cleavage under pyrolysis and combustion. It was conducted using a Mettler-Toledo TGA/SDTA851 ${ }^{\mathrm{e}}$ (Mettler-Toledo, Inc., Columbus, $\mathrm{OH}$, USA). An approximately $5 \mathrm{mg}$ sample was loaded into an alumina pan and vaporized (from $25^{\circ} \mathrm{C}$ to $600^{\circ} \mathrm{C}$, at a heating rate of $10^{\circ} \mathrm{C} \mathrm{min}{ }^{-1}$ ) under a nitrogen atmosphere with a flow rate of $20 \mathrm{~mL} \mathrm{~min}^{-1}$ (standard temperature and pressure). A heating rate of $10^{\circ} \mathrm{C} \mathrm{min}^{-1}$ was selected for the termite-chewed softwood and undigested softwood control.

\section{Mathematical analysis of thermodegradation}

A model consisting of two independent simultaneous reactions was employed to describe the thermodegradation kinetic changes of termite-chewed softwood using the integral method of Coats and Redfern [55]. In this model, each reaction stage was assumed to be first order in the formulation of the kinetic model. The integral equation is cited in Yang et al. [56] as follows:

$$
\ln \left[\frac{-\ln (1-\alpha)}{T^{2}}\right]=\ln \left(\frac{A \mathrm{R}}{\beta E}\right)-\frac{E}{\mathrm{RT}}
$$

for which, $\alpha=\frac{w_{0}-w}{w_{0}-\mathrm{w}_{\mathrm{f}}}$, and $\beta=\frac{\mathrm{d} T}{\mathrm{~d} t}=$ constant and where, $T$ is the absolute temperature (K), $A$ is the preexponential or frequency factor $\left(\mathrm{s}^{-1}\right), \mathrm{R}$ is the gas constant $\left(\mathrm{Jmol}^{-1} \mathrm{~K}^{-1}\right), E$ is the activation energy $\left(\mathrm{Jmol}^{-1}\right), w$ is the mass fraction present at any time, $\mathrm{w}_{0}$ is the initial mass fraction, and $\mathrm{w}_{\mathrm{f}}$ is the mass fraction at infinity.
Plotting $\ln \left[g(\alpha) / \mathrm{T}^{2}\right]$ versus $1 / \mathrm{T}$ results in a straight line with a slope of $-E / R$ and a $y$ intercept of $\ln [(A R) /$ $(\beta E)]$, providing the values of $\mathrm{E}$ and $\mathrm{A}$.

\section{Additional material}

Additional file 1: Pyrogram. Py-GC/MS spectrum of the whole guts of two termites starved for 40 hours. The appeared peaks represent $\mathrm{CO}_{2}$ and fatty acids, respectively. Non-existence of pyrolysate from lignin, cellulose or hemicellulose suggested complete evacuation of the gut contents.

\section{Acknowledgements}

This work was financially supported by the Agricultural Research Center of Washington State University (WSU).

\section{Authors' contributions}

JK and DL conceived and designed the experiments. JK and DG performed the experiments. JK and DL analyzed the data. SC contributed reagents, materials and analysis tools. JK and DL wrote the paper. SC mentored and revised the paper. All authors read and approved the final manuscript.

\section{Competing interests}

The authors declare that they have no competing interests.

Received: 12 September 2011 Accepted: 5 March 2012

Published: 5 March 2012

\section{References}

1. Prins RA, Kreulen DA: Comparative aspects of plant cell walls digestion in insects. Anim Feed Sci Technol 1991, 32:101-118.

2. Chaffron S, von Mering C: Termites in the woodwork. Genome Biol 2007, 8:229.

3. Yoshimura T: Contribution of the Protozoan fauna to nutritional physiology of the lower termite, Coptotermes formosanus Shiraki (Isoptera, Rhino termitidae). Wood Res 1995, 82:68-129.

4. Ke J, Sun J, Nguyen HD, Singh D, Lee KC, Beyenal H, Chen S: In situ oxygen profiling and lignin modification in guts of wood-feeding termites. Insect Sci 2010, 17:277-299.

5. Ke J, Singh D, Chen S, Yang X: Thermal characterization of softwood lignin modification by termite Coptotermes formosanus (Shiraki). Biomass Bioenergy 2011, 35:3617-3626.

6. Ke J, Laskar DD, Singh D, Chen S: In situ lignocellulosic unlocking mechanism in termite for carbohydrate hydrolysis, critical lignin modification. Biotechnol Biofuels 2011, 4:17-27.

7. Fujita A, Hojo M, Aoyagi T, Hayashi Y, Arakawa G, Tokuda G, Watanabe H: Details of the digestive system in the midgut of Coptotermes formosanus Shiraki. J Wood Sci 2010, 56:222-226.

8. Li L, Fröhlich J, Pfeiffer $P$, König H: Termite gut symbiotic archaezoa are becoming living metabolic fossils. Eukaryotic Cell 2003, 2:1091-1098.

9. Emerson AE: Termite nests-a study of the phylogeny of behavior. Ecol Monogr 1938, 8:247-284.

10. Oshima M: Formosan termites and methods of preventing their damage. Phil Jour Sci 1919, 15:319-383.

11. Reinhard J, Kaib M: Thin-layer chromatography assessing feeding stimulation by labial gland secretion compared to synthetic chemicals in the subterranean termite Reticulitermes santonensis. J Chem Ecol 2001, 27:175-187.

12. Fujita A, Minamoto T, Shimizu I, Abe T: Molecular cloning of lysozymeencoding cDNAs expressed in the salivary gland of a wood-feeding termite, Reticulitermes speratus. Insect Biochem Mol Biol 2002, 32:1615-1624.

13. Nakashima K, Watanabe H, Saitoh H, Tokuda G, Azuma Jl: Dual cellulosedigesting system of the wood-feeding termite, Coptotermes formosanus Shiraki. Insect Biochem Mol Biol 2002, 32:777-784. 
14. Veivers PC, Musca AM, O'Brien RW, Slaytor M: Digestive enzymes of the salivary glands and gut of Mastotermes darwiniensis. Insect Biochem 1982, 12:35-40.

15. Tokuda G, Saito $H$, Watanabe $H$ : A digestive $\beta$-glucosidase from the salivary glands of the termite, Neotermes koshunensis (Shiraki): distribution, characterization and isolation of its precursor CDNA by $5^{\prime}$ and 3'-RACE amplifications with degenerate primers. Insect Biochem Molec 2002, 32:1681-1689.

16. Todaka N, Lopez CM, Inoue T, Saita K, Maruyama J, Arioka M, Kitamoto K, Kudo T, Moriya S: Heterologous expression and characterization of an endoglucanase from a symbiotic protist of the lower termite, Reticulitermes speratus. Appl Biochem Biotech 2010, 160:1168-1178.

17. Inoue T, Murashima K, Azuma Jl, Sugumoto A, Slaytor M: Cellulose and xylan utilisation in the lower termite Reticulitermes speratus. J Insect Physiol 1997, 43:235-242.

18. Coy MR, Salem TZ, Denton JS, Kovaleva ES, Liu Z, Barber DS, Campbell JH, Davis DC, Buchman GW, Boucias DG, Scharf ME: Phenol-oxidizing laccases from the termite gut. Insect Biochem Mol Biol 2010, 40:723-732.

19. Noirot C: Glands and secretions. In Biology of the Termites. Edited by: Krishna K, Weesner FM. New York: Academic Press; 1969:89-123.

20. Hogan M, Veivers PC, Slaytor M, Czolij RT: The site of cellulose breakdown in higher termites (Nasutitermes walkeri and Nasutitermes exitiosus). J Insect Physiol 1988, 34:891-899.

21. Mednikova TK: Effect of caste differences on salivary gland functions in the termite Anacanthotermes ahngerianus. Zh Evol Biokhim Fiziol 1991, 27:86-91.

22. Kaib M, Ziesmann J: The labial gland in the termite Schedorhinotermes lamanianus (Isoptera, Rhinotermitidae), morphology and function during communal food exploitation. Insectes soc 1992, 39:373-384.

23. Reinhard J, Kaib M: Interaction of pheromones during food exploitation by the termite Schedorhinotermes Iamanianus. Physiol Entomol 1995, 20:266-272.

24. Reinhard J, Hertel H, Kaib M: Feeding stimulating signal in labial gland secretion of the subterranean termite Reticulitermes santonensis. J Chem Ecol 1997, 23:2371-2381.

25. Ke J, Laskar DD, Chen S: Biodegradation of hardwood lignocellulosics by the western poplar clearwing borer, Paranthrene robiniae (Hy. Edwards). Biomacroomolecules 2011, 12:1610-1620.

26. Schwarzinger $C$, Leid M, Putz R: Analysis of wood polymer composites by two-stage pyrolysis-GC/MS. J Anal Appl Pyrolysis 2008, 83:213-219.

27. del Río JC, Gutiérrez A, Rodríguez IM, Ibarra D, Martínez ÁT: Composition of non-woody plant lignins and cinnamic acids by Py-GC/MS, Py/TMAH and FT-IR. J Anal Appl Pyrolysis 2007, 79:39-46.

28. Yokoi $H$, Nakase $T$, Ishida $Y$, Ohtani $H$, Tsuge $S$, Sonoda $T$, Ona T: Discriminative analysis of Eucalyptus camaldulensis grown from seeds of various origins based on lignin components measured by pyrolysis-gas chromatography. J Anal Appl Pyrolysis 2001, 57:145-152.

29. Singh D, Zeng J, Laskar DD, Lee D, Hillcox W, Chen S: Investigation of wheat straw biodegradation by Phanerochaete chrysosporium. Biomass Bioenergy 2010, 34:1030-1040.

30. Nakagame S, Chandra RP, Kadla JF, Saddler JN: Enhancing the enzymatic hydrolysis of lignocellulosic biomass by increasing the carboxylic acid content of the associated lignin. Biotechnol Bioeng 2010, 108:538-548.

31. Pan X: Role of functional groups in lignin inhibition of enzymatic hydrolysis of cellulose to glucose. J Biobased Mater Bioenergy 2008, 2:25-32.

32. Ibarra D, del Río JC, Gutiérrez A, Rodríguez IM, Romero J, Martínez MJ, Martínez AT: Chemical characterization of residual lignins from eucalypt paper pulps. J Anal Appl Pyrolysis 2005, 74:116-122.

33. Martínez AT, Almendros G, González-Vila FJ, Fründ R: Solid-state spectroscopic analysis of lignins from several Austral hardwoods. Solid State NMR 1999, 15:41-48.

34. Faix O: Fourier transform infrared spectroscopy. In Methods in Lignin Chemistry. Edited by: Lin SY, Dence CW. Berlin: Springer-Verlag; 1992:83-109.

35. Jakab E, Várhegyi G, Faix O: Thermal decomposition of polypropylene in the presence of wood-derived materials. J Anal Appl Pyrolysis 2000, 56:273-285.

36. Sharypov VI, Marin N, Beregovtsova NG, Baryshnikov SV, Kuznetsov BN, Cebolla VL, Weber JV: Co-pyrolysis of wood biomass and synthetic polymer mixtures Part I, influence of experimental conditions on the evolution of solids, liquids and gases. J Anal Appl Pyrolysis 2002, 64:15-28.
37. Faix O, Jakab E, Till F, Székely T: Study on low mass thermal degradation products of milled wood lignins by thermogravimetry-massspectrometry. Wood Sci Technol 1988, 22:323-334.

38. Haykiri-Acma H, Yaman S, Kucukbayrak S: Comparison of the thermal reactivities of isolated lignin and holocellulose during pyrolysis. Fuel Process Technol 2010, 91:759-764.

39. Demirba A: Mechanisms of liquefaction and pyrolysis reactions of biomass. Energ Convers Manage 2000, 41:633-646.

40. Li J, Henriksson G, Gellerstedt G: Lignin depolymerization/ repolymerization and its critical role for delignification of aspen wood by steam explosion. Bioresource Technol 2007, 98:3061-3068.

41. Yang $H$, Yan $R$, Chen $H$, Lee DH, Zheng C: Characteristics of hemicellulose, cellulose and lignin pyrolysis. Fuel 2007, 86:1781-1788.

42. Ke J, Singh D, Chen S: Aromatic compound degradation by the woodfeeding termite Coptotermes formosanus (Shiraki). Int Biodeterior Biodegrad 2011, 65:744-756.

43. Geib SM, Filley TR, Hatcher PG, Hoover K, Carlson JE, Jimenez-Gasco MM, Nakagawa-Izumi A, Sleighter RL, Tien M: Lignin degradation in woodfeeding insects. PNAS 2008, 105:12932-12937.

44. Breznak JA: Intestinal microbiota of termites and other xylophagous insects. Annu Rev Microbiol 1982, 36:323-343.

45. Rouland C: Symbiosis with fungi. In Termites: Evolution, Sociality, Symbioses, Ecology. Edited by: Abe T, Bignell DE, Higashi M. Dordrecht, The Netherlands: Kluwer Academic; 2000:289-306

46. Itakura S, Ueshima K, Tanaka H, Enoki A: Degradation of wood components by subterranean termite, Coptotermes formosanus. Mokuzai Gakkaishi 1995, 41:580-586.

47. König H, Fröhlich J, Hertel H: Diversity and lignocellulolytic activities of cultured microorganisms. In Intestinal Microorganisms of termites and other invertebrates. Edited by: König H, Varma A. Berlin: Springer-Verlag; 2006:271-301.

48. Prins RA, Kreulen DA: Comparative aspects of plant cell wall digestion in insects. Anim Feed Sci Tech 1991, 32:101-118.

49. Kuroda K, Yamaguchi A: Classification of Japanese softwood species by pyrolysis-gas chromatography. J Anal Appl Pyrolysis 1994, 33:51-59.

50. Nazarczuk RA, O'Brien RW, Slaytor M: Alteration of the gut microbiota and its effect on nitrogen metabolism in termites. Insect Biochem 1981, 11:267-275.

51. Sreerama L, Veerabhadrappa PS: Isolation and properties of carboxylesterases of the termite gut-associated fungus, Xylaria nigripes. $\mathrm{K}$., and their identity from the host termite, Odentotermes horni. W., midgut carboxylesterases. Int J Biochem 1993, 25:1637-1651.

52. liyama $\mathrm{K}$, Wallis AFA: Determination of lignin in herbaceous plants by an improved cetyl bromide procedure. J Sci Food Agric 1990, 51:145-161.

53. Blee $K$, Choi JW, O'Connell AP, Jupe SC, Schuch W, Lewis NG, Bolwell GP: Antisense and sense expression of CDNA coding for CYP73A15, a class II cinnamate-4-hydroxylase, leads to a delayed and reduced production of lignin in tobacco. Phytochemistry 2001, 57:1159-1166.

54. Zimbardi F, Viggiano D, Nanna F, Demichele M, Cuna D, Cardinale G: Steam explosion of straw in batch and continuous systems. Appl Biochem Biotechnol 1999, 77:117-125.

55. Coats AW, Redfern JP: Kinetic parameters from thermogravimetric data. Nature 1964, 201:69.

56. Yang $X$, Zeng $Y$, Zhang $X$ : Influence of biopreatreatment on the characte of corn stover lignin as shown by thermogravimetric and chemical structural analyses. BioResources 2010, 5:488-498.

\section{doi:10.1186/1754-6834-5-11}

Cite this article as: Ke et al: Advanced biorefinery in lower termiteeffect of combined pretreatment during the chewing process. Biotechnology for Biofuels 2012 5:11 